\title{
AS INTERFERÊNCIAS DA LEGISLAÇÃO AMBIENTAL SOBRE OS MEIOS DE VIDA DAS COMUNIDADES RURAIS E O PAPEL DA EXTENSÃO RURAL
}

\author{
Marlene de Paula Pereira \\ Maria Izabel Vieira Botelho ${ }^{2}$
}

\begin{abstract}
Resumo
O trabalho teve por objetivo discutir os impactos da legislação ambiental sobre os meios de vida dos agricultores ${ }^{3}$ familiares e o papel da extensão rural como possível mediadora entre as necessidades de quem lida com a terra e os interesses daqueles que produzem as leis. Para alcançar tal objetivo recorreu-se a uma revisão da literatura acerca de meios de vida, dentre outras que foram consideradas pertinentes. Através de exemplos retirados das próprias leis, demonstrou-se a existência das interferências acima mencionadas e a necessidade de um diálogo mais efetivo, que poderá tornar-se possível por meio do fortalecimento da figura do agente de extensão rural, que tem a possibilidade de tornar-se um mediador entre as necessidades dos agricultores e a vontade do Estado no momento da elaboração de leis agroambientais.
\end{abstract}

Palavras chave: lei, meios de vida, agricultores.

\section{THE INTERFERENCE OF ENVIRONMENTAL LEGISLATION ON THE LIVELIHOODS OF RURAL COMMUNITIES AND THE ROLE OF RURAL EXTENSION}

\begin{abstract}
The study aimed to discuss the impacts of environmental regulations on the livelihoods of family farmers and rural extension's role as a possible mediator between the needs of anyone who deals with the land and the interests of those who produce the laws. To achieve this goal was a literature review about livelihoods, among others that were considered relevant. Through examples drawn from the very laws, demonstrated the existence of the aforementioned interference and the need for a more effective dialogue, which may become possible through the strengthening of the rural extension agent, which has the possibility to become a mediator between

\footnotetext{
${ }^{1}$ Professora do Instituto Federal Sudeste de MG, campus Barbacena; Doutoranda na Universidade Federal de Viçosa, departamento de Extensão Rural. Membro do grupo de pesquisa TAS- Território, Ambiente e Socialidade, campus Barbacena.

${ }^{2}$ Bacharela em Ciências Econômicas - PUC/SP. Mestrado em Sociologia Rural (UNICAMP). Doutorado em Sociologia, UNESP. Pós-Doutorado. Wageningen University. Professora Associada do Departamento de Economia Rural da Universidade Federal de Viçosa.

${ }^{3}$ Neste trabalho, o termo "agricultor familiar" está sendo utilizado em sua acepção ampla, como sinônimo de "pequeno proprietário rural", ou seja, aquele que cultiva pequenas glebas de terra, tendo como força de trabalho predominante a familiar e que tenha o controle sobre o processo produtivo. 98
} 
the needs of farmers and the will of the State at the time of the development of agrienvironmental laws.

Keywords : law, livelihoods, farmers.

\section{INTRODUÇÃO}

O Direito, ao mesmo tempo em que regula a vida em sociedade, interfere na maneira como as pessoas se comportam, no modo como utilizam os recursos da natureza, na forma como agem em relação aos hábitos e costumes adquiridos. Isto porque cumprir a lei não é uma opção, e sim uma obrigação, visto que o descumprimento traz como consequência uma punição. $E$ essa punição pode significar o enquadramento do sujeito na categoria "criminoso", que, além de trazer consequências legais, possui forte carga de desprestígio social.

Neste trabalho, propõe-se uma discussão para além do papel regulador do Direito. Pretende-se buscar entender como a lei e o Direito representam elementos constitutivos dos meios de vida, ou seja, como a legislação, ao regular o modo como as condutas devem ser orientadas, interfere na maneira das pessoas viverem, trabalharem e, assim, garantirem a sua reprodução social. Objetiva-se, ainda, refletir a respeito do papel da extensão rural no processo de discussão e elaboração da lei como um possível mediador entre a vontade manifestada pelo Estado e os interesses dos agricultores, especialmente os de pequeno porte.

O interesse pelo tema ora apresentado ocorreu em razão, principalmente, do contexto das discussões ocorridas para aprovação da Lei 12.651/2012, conhecida como "Novo Código Florestal". Certamente, o Código Florestal não é a única lei que provoca impactos nos meios de vida dos agricultores familiares, mas uma pesquisa realizada no Fórum da Comarca de Viçosa - MG, demonstrou que, do quantitativo de processos referentes questões ambientais, $64 \%$ versam sobre o uso indevido de Áreas de Preservação Permanente (APPs); 32\% dos processos referem-se a utilização de área de Reserva Legal (32\%); 3\% dos processos referemse a outros tipos de infrações (3\%).

Desse modo, nota-se que as infrações ligadas ao uso indevido de APPs e reserva legal (previsões que constam do Código Florestal) representam 96\% do total de ocorrências que tramitam na Vara. Normalmente, o conflito instala-se porque, se por um lado, a legislação ambiental tem como uma das principais finalidades proteger o meio ambiente, estabelecendo padrões e procedimentos que contribuam para preservação dos recursos naturais, por outro, estas determinações podem significar a redução da área de plantio, e, portanto, da produção e da renda.

Estudos comprovam que os principais problemas observados entre os agricultores e a legislação decorrem das restrições que a lei impõe ao agricultor ao instituir áreas de conservação nas propriedades rurais como é o caso das Áreas de Preservação Permanente (APP) e Reserva Legal (RL) (TOURINHO e PASSOS, 2006; JACOVINE et al., 2008; COSTA et al., 2013).

As Áreas de Preservação Permanente (APP)s podem ser definidas a área, coberta ou não por vegetação nativa, com a função ambiental de preservar os recursos hídricos, a paisagem, a estabilidade geológica e a biodiversidade, facilitar o fluxo gênico de fauna e flora, proteger o solo e assegurar o bem-estar das 
populações humanas. Já a reserva legal é área localizada no interior de uma propriedade ou posse rural, necessária ao uso sustentável dos recursos naturais, à conservação e reabilitação dos processos ecológicos, à conservação da biodiversidade e ao abrigo e proteção de fauna e flora nativas (BRASIL, Lei $\mathrm{n}$. $12.651 / 2012$ ).

A reserva legal é um dos instrumentos legais que mais causa polêmica quando se fala da necessidade de assegurar os meios de vida. As discussões sobre o Código Florestal atualmente em vigor comprovam este fato. Ambientalistas defendem a sua preservação, o setor produtivo argumenta se tratar de intromissão indevida do Estado sobre a propriedade privada, o que diminuiria a competitividade da agricultura e a capacidade de produção do país.

O atual Código Florestal (Lei 12.651/12) foi aprovado em maio de 2012, após anos de muita discussão entre parlamentares, representantes do governo, ruralistas e ambientalistas. O foco da discussão girou em torno de dois argumentos centrais: o primeiro, que o Código Florestal em vigor datava de 1965 e, por essa razão, já não mais acobertava uma série de situações que a modernização da agricultura e a urbanização trouxeram; e o segundo, que era necessário fazer alterações na lei de modo a viabilizar a sobrevivência da agricultura familiar.

Apesar dos diversos interesses envolvidos, o confronto resumiu-se, mais uma vez, na disputa entre os "ruralistas", que defendiam a necessidade de o Código de 1965 ser substituído por uma lei nova, e os "ambientalistas", que criticavam o projeto de lei e defendiam a manutenção do Código de 1965.

Dentre os ambientalistas estavam ecologistas, membros de organizações não governamentais como a Greenpeace, a Amigos da Terra e o Instituto do Homem e Meio Ambiente da Amazônia (Imazon), além de representantes de órgãos como o Ministério Público. Do lado oposto, dentre os ruralistas, estavam, latifundiários, a Confederação Nacional da Agricultura, e a Associação Brasileira dos Exportadores de Carne (Abiec).

Entretanto, mesmo com a aprovação e entrada em vigor, as discussões não se encerraram. O Novo Código Florestal continua gerando polêmicas e fomentando discussões em diversos níveis. Atualmente, tramitam no Supremo Tribunal Federal três ações que questionam a constitucionalidade dessa lei ${ }^{4}$. O principal fundamento das ações constitucionais é o fato de a lei, em vários artigos, ter diminuído a proteção ambiental, o que, de acordo com o Direito Ambiental, representa um inaceitável retrocesso.

Outro argumento utilizado contra o Código é o desrespeito ao parágrafo primeiro do artigo 24 da Constituição Federal que prevê que no âmbito da legislação concorrente, a competência da União limitar-se-á a estabelecer normas gerais. De acordo com o próprio artigo 1ํ do Código Florestal, o objetivo desta lei é estabelecer normas gerais sobre proteção da vegetação, Áreas de Preservação Permanente, Reserva Legal, Exploração Florestal, controle e prevenção de incêndios e, ainda, prever instrumentos econômicos e financeiros para o alcance de seus objetivos. Entretanto, de acordo com alguns autores (MUKAI, 2012 ; ANTUNES, 2007; FRANCO, 2005; MENHEM, 2007), embora pretenda ser uma norma geral, o Código Florestal perde esse caráter na medida em que chega a especificar detalhes que não condizem com as características das normas gerais.

\footnotetext{
${ }^{4}$ ADI 4901, ADI 4902, ADI 4903, Supremo Tribunal Federal.
} 
Muitos trabalhos já foram desenvolvidos com vistas a buscar entender o processo de elaboração do Código Florestal, ou mesmo, compreender os conflitos e tensões que esta lei gera em relação ao uso da terra, especialmente em relação à agricultura familiar (HAUER, 2009; LELIS, 2011; ABREU, 2011; TOURINHO e PASSOS, 2006; JACOVINE et al., 2008; COSTA et al., 2013).

A originalidade do presente trabalho, entretanto, encontra-se no fato abordar os impactos que a legislação ambiental, especialmente o Código Florestal, traz para o agricultor familiar no que se refere aos seus meios de vida.

Os "meios de vida" ou livelihoods", neste trabalho, serão entendidos como as estratégias que os sujeitos lançam mão para sobreviver em contextos sociais, notadamente marcados por crises e imposições das mais diversas (BEBBINGTON (1999), PERONDI (2007), CHAMBERS e CONWAY (1992), ELLIS (2000), HAAN (2000), HEBINK (2007).

Portanto, nesta pesquisa, pensar-se-á a lei como um elemento constitutivo dos meios de vida, na medida em que esta determina o que se deve fazer, o que não se deve fazer, como se deve fazer e estas determinações interferem na maneira como as pessoas organizam suas estratégias de sobrevivência. Permeando essa discussão, propõe-se também uma reflexão a respeito do papel da extensão rural no sentido de mediar um possível diálogo entre os interesses dos diversos tipos de agricultores (grandes, pequenos, ricos, pobres) e as leis que a eles afetam, como é o caso das leis ambientais.

Sabe-se que uma lei, além da função de regular, deve ter também outras funções sociais. Assim, ao instituir uma punição, a lei tem a finalidade de estimular determinado comportamento e desestimular outros, mas estas interferências têm consequências sociais e econômicas. Nesse sentido, será feita uma abordagem da lei, não como um instrumento normativo, mas como um instrumento de intervenção social, muitas vezes, incapaz de distribuir os bônus e os ônus de modo equitativo.

\section{AS INTERFERÊNCIAS DA LEI AMBIENTAL SOBRE OS MEIOS DE VIDA DAS COMUNIDADES RURAIS}

Na medida em que se pensa em uma atividade que lida diretamente com o capital ecológico, é quase impossível imaginar que em algum momento não haverá um conflito ou, ao menos, um desencontro entre o que determina a lei ambiental e o que necessita o agricultor. Somente no Código Florestal, o termo "é vedada" aparece quinze vezes, o que demonstra que para atender aos fins propostos, esta lei precisa impor outro modo de o agricultor lidar com a natureza. ${ }^{6}$ As discussões que antecederam a aprovação dessa lei, de certo modo, ventilaram esta questão, tanto que uma das alterações mais comentadas acerca do novo Código Florestal é a criação do CAR - Cadastro Ambiental Rural, que consiste no registro público eletrônico de âmbito nacional, obrigatório para todos os imóveis rurais, com a finalidade de integrar as informações ambientais das propriedades, e que, dentre

2 No Dictionário de Língua Inglesa Cambridge livelihoods é definido como "way someone earns" ou "como se faz para ganhar a vida" (CAMBRIDGE, 2005, p.744).

6 . Art 4 , parágrafo $4-(.$.$) vedada nova supressão de áreas de vegetação nativa, salvo autorização do órgão$ ambiental competente do Sistema Nacional do Meio Ambiente - Sisnama. Art 7, parágrafo 3 - (...)é vedada a concessão de novas autorizações de supressão de vegetação enquanto não cumpridas as obrigações previstas no $\S 1^{\circ}$. Art. 38. É proibido o uso de fogo na vegetação (...). 
outras coisas, afasta a necessidade de averbação da Reserva Legal junto ao Cartório de Registro de Imóveis. Esse aspecto é relevante porque a grande maioria dos casos que chegavam a constituir processos administrativos e judiciais era justamente a falta de averbação da reserva legal, em razão, principalmente, da falta de condições dos agricultores de arcar com as taxas.

Pela nova legislação, a área de Reserva Legal deverá ser registrada no órgão ambiental competente por meio de inscrição no CAR, que irá armazenar a base de dados para controle, monitoramento e planejamento ambiental. As regras pertinentes ao funcionamento do CAR foram detalhadas por meio da Instrução Normativa n. 2, de 05 de maio de 2014, emitida pelo Ministério do Meio Ambiente (MMA) (D.O.U., 6 de maio de 2014, p. 59).

Observa-se que com essa alteração, o Código Florestal de 2012 isenta o proprietário rural do pagamento da taxa cartorial, pois a averbação não mais deverá ser realizada em cartório. Entretanto, o proprietário não está isento de cumprir os demais requisitos, que embora tenham sido simplificados, não deixaram de existir. Trata-se da necessidade de apresentar ao órgão ambiental documento de identificação do proprietário, do imóvel e croqui indicando o perímetro do imóvel, as áreas de preservação permanente e os remanescentes que formam a reserva legal (Art. 14, Instrução Normativa 02, 2014, MMA).

Além das dificuldades para cumprir os requisitos necessários para o cadastro, a própria inscrição no SISCAR (Sistema para Cadastro Ambiental Rural) é uma dificuldade para alguns agricultores, que comumente não têm acesso à internet, nem recebem apoio de nenhum órgão de assistência.

De acordo com o Código Florestal e com a Instrução Normativa n. 2, do MMA, o proprietário de até quatro módulos fiscais, que julgar necessário, poderá solicitar o apoio institucional ou de entidade habilitada para realizar o cadastro no CAR. Entretanto, nenhuma das duas normas esclarece qual é a instituição ou entidade que deve prestar esse apoio e nem de que maneira. Os órgãos administrativos alegam que não dispõem de infraestrutura técnica para realizar qualquer ajuda, e, enquanto isso, muitos proprietários continuam na ilegalidade, pois não dispõem de meios para viabilizar toda a documentação necessária para regularizar a situação.

Nota-se, assim, que a legislação é muito mais do que um conjunto de instrumentos para regulação social. De modo geral, a lei é um elemento constituinte dos meios de vida das pessoas, no sentido de que, ao "regular" as condutas, estabelece o pode e o que não pode ser feito, impõe mudanças de atitude e consequências pela não adequação aos padrões exigidos. Segundo Thompson (1987), a lei não pode ser vista como simples aparato do Estado. Na verdade, ela é uma mediação para que ocorre entre a subordinação, o paternalismo, a deferência. $\mathrm{O}$ autor faz referência aos interesses que permeiam o processo de elaboração e aplicação da lei e que a impedem de ser genérica e abstrata, como normalmente é tratada.

Considerando que existe uma relação de proximidade entre agricultura e meio ambiente, a lei ambiental passa a ser um elemento que interfere diretamente nos meios de vida dos agricultores. Segundo Ploeg (2008, p. 4), "a produção camponesa é baseada numa relação de troca não mercantilizada com a natureza", ou seja, o capital ecológico muitas vezes é a maior riqueza da família. A partir dessa necessidade é que o presente trabalho pretende buscar entender como tais agricultores vão conduzir os processos no mundo rural, como vão utilizar os recursos de que dispõem, de que tipos de tecnologias e redes sociais vão se valer, 
como vão desenvolver suas estratégias de reprodução social através do trabalho e do uso do ambiente.

O gráfico abaixo mostra a distribuição das infrações ambientais que deram origem a processos que tramitam na $2^{\underline{a}}$ vara Cível da Comarca de Viçosa. As infrações foram separadas por área onde ocorreram, com o intuito de demostrar o impacto da legislação ambiental sobre as pessoas do meio rural. A parte escura representa as infrações ambientais que ocorreram na área rural (67\%) e a parte mais clara representa as infrações que ocorreram na área urbana (33\%).

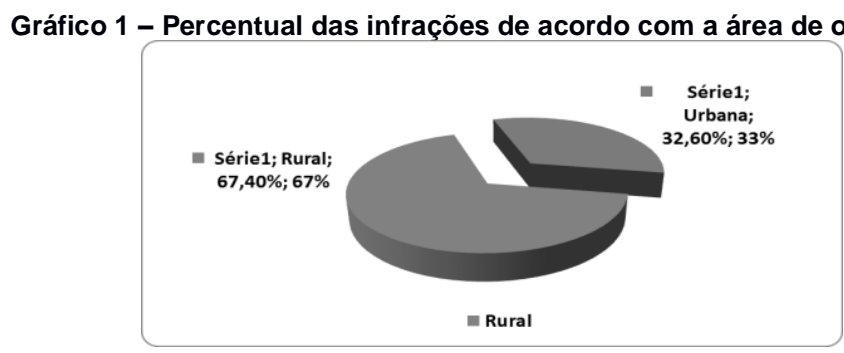

Distribuição das infrações descritas nos processos que tramitam na $2^{-\underline{a}}$ Vara Cível da Comarca de Viçosa, de acordo com a área (urbana ou rural), referente ao período de 2010 a 2013. Fonte: Ministério Público do Estado de Minas Gerais. Elaboração do gráfico: José Antônio Brilhante de São José.

A abordagem dos meios de vida (livelihoods) é uma ferramenta analítica que tem sido utilizada com maior ênfase nos estudos sobre a pobreza rural no mundo, principalmente, no continente africano, pois apresenta uma grande efetividade em explicar o modo como as pessoas fazem para sobreviver em situações de risco e/ou crises ambientais, sociais ou econômicas (PERONDI, 2007).

Os primeiros autores a fazerem uso desta abordagem foram Robert Chambers e Gordon Conway, no trabalho "Sustainable rural livelihoods: practical concepts for the 21st century," em 1992. Esta abordagem surge, portanto, no bojo dos debates sobre desenvolvimento rural e desenvolvimento rural sustentável.

No Brasil, o termo "meios de vida" foi cunhado por Antônio Cândido (1958), na obra "Parceiros do Rio Bonito", na qual o autor procurava "conhecer os meios de vida num grupamento de caipiras: quais são, como se obtêm, de que maneira se ligam à vida social, como refletem as formas de organização e as de ajuste ao meio" (CÂNDIDO, 2003, p. 21).

Segundo Haan (2000), a primeira versão do que hoje seria a abordagem dos meios de vida foi a noção de genre de vie introduzida por Vidal de la Blanche no século XIX. Naquela época, a geografia havia recém sido reconhecida como uma disciplina acadêmica e havia uma forte convicção no poder do ambiente físico de modelar as atividades humanas, conduzindo à valorização das características físicas da paisagem.

Entretanto, logo depois da Segunda Guerra Mundial, o conceito de meios de vida quase desapareceu dos estudos geográficos sobre o desenvolvimento frente às abordagens da teoria da dependência e as neo-marxistas. Somente a partir dos 
anos 1980, quando o estruturalismo entrou em crise é que houve espaço, já nos anos de 1990, para a abordagem dos meios de vida (HAAN e ZOOMERS, 2003).

Os primeiros estudos que avaliavam o comportamento das pessoas pobres tinham a tendência de considerá-las como vítimas passivas e infortunadas do sistema. Os estudos sobre os espaços domésticos e sobre as estratégias domésticas passaram a dar um papel mais proativo aos pobres, um papel que permitia entender como eles providenciavam o seu próprio sustento a despeito da falta de acesso aos serviços e à renda adequada (PERONDI, 2007).

Segundo Haan e Zoomers (2005), muitos dos estudos sobre o espaço doméstico que aparecem a partir dos anos de 1980 eram conduzidos pelo princípio de que as "novas economias domésticas" deveriam ser focadas na alocação da terra e do trabalho, como também nas estratégias de renda e usavam, como ferramenta explicativa, o modelo microeconômico da economia doméstica. Por consequência, os estudos sobre os espaços domésticos utilizavam como conceito-chave a "estratégia de sobrevivência".

Entretanto, enquanto muitos destes estudos concluíam de forma pessimista que os espaços domésticos pobres estavam sendo excluídos dos benefícios do crescimento econômico, surgiu, no início dos anos 1990, uma nova geração de estudos otimistas numa perspectiva denominada "livelihoods" (meios de vida), que analisava o comportamento das pessoas de uma forma mais ampla, não apenas encapsulada na família, e demostrava que as pessoas eram hábeis em sobreviver (PERONDI, 2007).

O termo meios de vida, comumente utilizado em relação aos processos do mundo rural, geralmente aborda as diferentes combinações de recursos que a população rural possa utilizar localmente como estratégia para construir suas formas de reprodução social através do trabalho (agrícola e não-agrícola), redes sociais acionadas, conhecimento, tecnologia, emprego, utilização de recursos naturais e outras formas de obtenção de renda (HENBICK, 2007).

Para Chambers e Conway (1992),

\begin{abstract}
os meios de vida compreendem as capacidades, ativos (estoques, recursos, direitos e acessos) e atividades necessárias para uma forma de viver: um meio de vida é sustentável quando pode lidar com estresses e perturbações, mantendo ou aumentando suas capacidades e ativos, e fornecendo oportunidades de meios de vida sustentável para as próximas gerações; e o qual contribui beneficamente com outros meios de vida no local ou global, em curto e longo prazo. (CHAMBERS e CONWAY, 1992, p. 6, tradução nossa).
\end{abstract}

O grupo de pesquisa liderado por Frank Ellis, também na Inglaterra, procurou consolidar o viés da diversificação na abordagem dos meios de vida. Para Ellis, é importante perceber a capacidade de diversificação dos meios de vida, uma capacidade que cria a diversidade em processos sociais e econômicos e que se reflete em fatores que pressionam e oportunizam as famílias para que diversifiquem os seus meios de vida, como também o seu local (ELLIS, 2000). É nas pegadas dessa diversificação, proposta por Ellis (2000), que este trabalho propõe pensar a lei como elemento que pressiona e oportuniza as famílias a mudar e redesenhar os meios de vida.

Em relação ao termo "ativos", Ellis (2000) destaca que em Chambers e Conway (1992) o termo engloba muitos componentes, alguns relacionados aos 
diferentes tipos de capital, na esfera econômica, portanto, enquanto outros relacionados à dimensão social, como "direitos", por exemplo.

Scoones (1998), seguindo a linha de Chambers e Conway (1992), identificou cinco tipos diferentes de capital: Capital Natural; Capital Físico; Capital Financeiro; Capital Humano; Capital Social.

Ellis (2000) utiliza a contribuição de Scoones (1998), referente à diferenciação dos ativos em seus cinco tipos de capitais; contudo, busca diferenciarse de Chambers e Conway (1992) em relação à noção de "acessos", atribuindo maior relevância a esta dimensão e chamando a atenção para a importância dos impactos que as relações sociais e as instituições mediadoras exercem nas capacidades que um indivíduo ou família tem para atenderem suas demandas de consumo.

Ellis (2000) destaca, portanto, a importância de se considerar fatores como gênero, família, classe social, casta, etnia, sistema de crenças, etc.. O autor fala, portanto, na importância de se considerar as "instituições", seguindo a definição elaborada por North como sendo as regras, ou constrangimentos e limitações socialmente construídos que moldam as ações e interações humanas. Mais uma vez ressalta-se a ligação deste trabalho com a abordagem de Ellis (2000), pois o que se pretende é exatamente considerar a lei como um elemento que altera os meios de vida, seja por impor, seja por proibir comportamentos.

Feitas essas considerações, Ellis (2000) define os meios de vida da seguinte forma:

meios de vida compreende os ativos (capital natural, físico, humano, financeiro e social), as atividades e o acesso a ambos (mediado pelas instituições e relações sociais), que juntos determinam os meios de vida de um indivíduo ou grupo familiar. (ELLIS, 2000, p. 10, tradução nossa)

O ponto de partida para análise dos meios de vida adotado por Ellis (2000) são os ativos que a família tem acesso. Por "ativos" o autor entende os estoques de capital que podem ser utilizados diretamente, ou indiretamente, para gerar os meios de sobrevivência ou sustentar o bem-estar material da família. Como em Scoones (1998), para Ellis (2000) os ativos podem ser divididos em cinco categorias: capital natural, capital financeiro, capital físico, capital humano e capital social. Contudo, o autor reconhece que o acesso aos ativos que compõem o "portfólio" dos meios de vida é mediado pelos diferentes contextos sociais, econômicos e políticos. Tal mediação ocorre por meio das instituições, das organizações e das relações sociais nas quais os indivíduos, ou grupos domésticos, estão inseridos.

Relações sociais, instituições e organização são os principais mediadores dos meios de vida porque eles envolvem as agências que inibem ou facilitam o exercício das capacidades e escolhas dos indivíduos ou das famílias. (ELLIS, 2000, p. 39, tradução nossa)

As estratégias dos meios de vida são compostas também por atividades. Estas geram os meios de sobrevivência e bem estar da família. Quanto maior a diversificação das estratégias, maiores serão as chances de se conseguir melhores padrões de vida para o grupo doméstico. Os processos de mediação junto a fatores exógenos (desastres climáticos, doenças, morte de membros da família, mudanças na lei, etc.) podem provocar a necessidade de adaptação e mudança nas estratégias 
dos meios de vida. As consequências das estratégias dos meios de vida adotadas podem acarretar em meios de vida mais estáveis e sustentáveis, ou não (DUGULIN, 2014).

Ellis (2000) divide as atividades em duas subcategorias: atividades baseadas em recursos naturais (extrativismo, agricultura, pecuária, etc.); e atividades não baseadas em recursos naturais (comércio, manufaturas, remessas externas em dinheiro a partir da migração, pensões e repasses de dinheiro público via políticas públicas e direitos sociais etc.).

A noção de meios de vida sempre reconheceu que é preciso considerar, em alguma medida, dimensões que extrapolam aspectos econômicos. Ellis (2000) trouxe uma grande contribuição neste sentido quando tenta atribuir maior peso em suas análises aos acessos que são necessariamente mediados por instituições e pelas relações sociais, dentro e fora da família. Este mesmo autor ainda alerta para o fato de que meios de vida não podem ser entendidos como sinônimo de renda, ou fontes de renda.

Contudo, mesmo chamando a atenção para tais questões, o fato dos autores citados anteriormente utilizarem termos e conceitos como "ativos" e "capitais" acaba destinando aos aspectos econômicos uma importância maior, em detrimento dos aspectos sociais e políticos (DUGULIN, 2014).

Bebbington (1999), em sua abordagem sobre meios de vida, retira o foco das estratégias de diversificação para acentuar a dificuldade de os agricultores acessarem, defenderem e manterem ativos, ampliando o debate para a questão do acesso e demonstrando que este envolve uma disputa entre os agricultores e outros atores sociais presentes em esferas mais amplas. $O$ autor enfatiza as relações de poder envolvidas na construção das estratégias.

A disputa a que Bebbington se refere pode ser claramente observada entre os agricultores e outros grupos quando se tem em vista a lei ambiental. As determinações da lei visando a preservação do meio ambiente impõem que os agricultores desenvolvam estratégias, seja para adaptarem-se, seja para burlarem as regras.

Vale ressaltar também a posição de Antônio Cândido (1958) sobre meios de vida, em que o autor refuta a dicotomia homem/natureza para ressaltar a importância da satisfação das necessidades na organização social. Segundo o autor, a maneira pela qual os homens produzem seus meios de subsistência depende, antes de mais nada, da natureza dos meios de subsistência que encontram prontos e que necessitam produzir. Este modo de produção não deve ser considerado apenas como reprodução da existência física dos indivíduos; ele já é uma espécie determinada da atividade destes indivíduos, uma determinada maneira de manifestar sua vida, uma determinada maneira de viver destes indivíduos (Marx, apud Cândido, 2003, p.31).

Para Candido, a importância deste ponto de vista consiste em colocar o fato social da organização no âmago da discussão dos problemas de subsistência. Complementa sua discussão, então, com Malinowski (1944), o qual demonstraria que a satisfação das necessidades já se situaria em pleno terreno institucional, desta forma, "as necessidades básicas não apenas dão lugar a reações culturais (cultural response) mas estas originam novos tipos de comportamento, que se tornam necessidades derivadas, indissoluvelmente ligadas àquelas" (MALINOWSKI, apud CANDIDO, 2003, p.31).

Hebinck (2007) também constrói uma concepção de meios de vida que extrapola a dimensão econômica. Para tentar escapar da tendência à 106 
sobrevalorização dos aspectos econômicos, o autor utiliza o termo "recursos" ao invés de "capitais". Segundo o autor, a noção de capital dificulta a análise dos componentes dos meios de vida não materiais, tais como redes sociais e vizinhança, tendendo a ignorar a importância desses recursos não materiais para a construção e constituição dos meios de vida. Portanto, de acordo com Hebinck (2007), o termo recursos seria mais adequado para analisar os meios de vida por possibilitar compreender como estes são utilizados e quais significados são atribuídos a eles pelos atores sociais.

Hebinck (2007) chama a atenção para o fato de que a noção de recursos não reflete somente qualidades biofísicas, mas também as relações sociais imbricadas e conectadas com as relações de poder que governam e moldam a realidade específica de acesso e usos dos diversos recursos pelos atores presentes numa determinada configuração social.

Hebinck (2007) destaca ainda, seguindo a contribuição de Ellis (2000), que meios de vida só pode ser compreendido quando é visto inserido em instituições, ou seja, em normas, regras e constrangimento que estão sujeitas as interações sociais numa determinada sociedade.

A utilização de determinados recursos reflete e está condicionada ao acesso, ou ao direito, sobre os meios de consegui-los. Aqui estão envolvidas as relações de poder e de capacidade de decisão nas diversas instâncias dentro da própria família, mas também em esferas sociais mais amplas. Neste sentido, é muito importante combinar a análise das regras e normas com os padrões de utilização dos recursos disponíveis. É o que se propõe neste trabalho.

É importante destacar ainda que vários autores insistem na afirmação de que a noção de meios de vida não pode ser entendida de forma estática. Ela deve ser sempre utilizada de forma contextualizada no espaço e no tempo, possibilitando a percepção das constantes mudanças (HEBINCK, 2007). Aqui reside uma das dificuldades de atribuir aos meios de vida uma definição mais delimitada. Ellis (2000) alerta para o risco de afixar uma definição, pois ela pode limitar a transmissão das mudanças e das diversas circunstâncias. Para o autor, a principal característica dos meios de vida rural nos países subdesenvolvidos é justamente sua capacidade de adaptação.

Henbick (2007) ressalta a importância dos aspectos não materiais, tais como percepção do mundo e significados que os atores sociais atribuem aos diversos recursos a que têm acessos e que influenciam de forma determinante nas escolhas e representatividade dentro do conjunto das estratégias dos meios de vida de um determinado grupo social.

É a partir desta visão ampla que, neste trabalho, entende-se a lei como elemento constituinte dos meios de vida, capaz de gerar alterações na vida do agricultor familiar quando determina maneiras específicas de se lidar com os recursos naturais, como a água ou as florestas e, ao mesmo tempo, apresenta punições para os casos de descumprimento.

E certo que esses agricultores desenvolvem "estratégias de sobrevivência" para lidar com estas dificuldades. Algumas vezes estas estratégias podem caracterizar uma mudança de postura, no sentido do enquadramento aos ditames legais; outras, podem representar o descumprimento, que será acompanhado de um processo/procedimento, multa, punição, e outras ainda, podem significar a opção por outro modo de vida, como o abandono da terra e a busca por um emprego urbano. 
Em todas as hipóteses vislumbra-se a situação em que a lei, de fato, atingiu os meios de vida dos agricultores e os modificou, revelando-se, portanto, um elemento constitutivo. Esse aspecto remete a uma reflexão a respeito de como estes agricultores que são mais gravemente atingidos (em geral, os de pequeno porte) encontram-se excluídos do processo de discussão e elaboração de leis que os alcançam diretamente.

\section{A INVISIBILIDADE DO PEQUENO AGRICULTOR E O PAPEL DA EXTENSÃO RURAL COMO MEDIADORA DO DEBATE}

Jessé Souza (2003) propõe a construção de um modelo teórico que explique a existência, nos dias de hoje, de uma parcela social que permanece ausente ao processo democrático. Segundo o autor, há uma singularidade no desenvolvimento das sociedades de capitalismo periférico, que é a formação histórica de um grande contingente populacional composto por marginalizados ou "desclassificados sociais", pessoas desvinculadas dos processos econômicos, sociais e políticos básicos da sociedade. Para Souza, ao mesmo tempo em que isso ocorreu, houve um processo de naturalização desta desigualdade que nos levou a formas perversas de subcidadania e marginalização. Ele afirma que a explicação para tais fatos pode ser encontrada a partir da análise do processo de modernização do país.

Lênio Streck (1998, p. 24), no mesmo sentido, afirma que existe o sobreintegrado ou sobrecidadão, que dispõe do sistema, mas a ele não se subordina, e o subintegrado ou subcidadão, que depende do sistema, mas a ele não tem acesso. O agricultor familiar, em muitos casos e em muitas regiões do país, faz parte dessa parcela de "subcidadãos", ausentes dos processos decisórios, da elaboração das leis e das políticas, embora diretamente afetado por elas.

Franco (1997, p. 14), em sua explicação a respeito da formação sui generis dessa mão de obra, que embora livre, não se integrou à produção mercantil, afirma:

A constituição desse tipo de humano prende-se à forma como se organizou a ocupação do solo, concedido em grandes extensões e visando culturas onerosas. Dada a amplitude das áreas apropriadas e os limites impostos à sua exploração pelo próprio custo das plantações, decorreu uma grande ociosidade das áreas incorporadas aos patrimônios privados, podendo, sem prejuízo econômico, serem cedidas para uso de outro. Essa situação possibilitou e consolidou a existência de homens destituídos da propriedade dos meios de produção, mas não de sua posse, e que foram plenamente submetidos às pressões econômicas decorrentes dessa condição. Assim, numa sociedade em que há concentração dos meios de produção, onde vagarosa, mas progressivamente, aumentam os mercados, paralelamente forma-se um conjunto de homens livres e expropriados que não conheceram os rigores do trabalho forçado e não se proletarizaram. Formou-se antes, uma 'ralé' que cresceu e vagou ao longo de quatro séculos: homens a rigor dispensáveis, desvinculados dos processos essenciais à sociedade.

Se considerarmos os processos de discussão das leis direcionadas à agricultura, podemos perceber os agricultores familiares como atores, ao mesmo 
tempo, 'presentes' e 'ausentes'. 'Presentes', porque são, com frequência, utilizados como argumento para aprovação de mudanças, mas, ao mesmo tempo, 'ausentes', porque pouco ou nada participam dos debates nas arenas públicas.

O Código Florestal, aprovado em 2012, é um exemplo atual dessa invisibilidade social e política desses agricultores. Ambos os lados (ambientalistas e ruralistas) diziam-se representantes dos interesses da agricultura familiar, que necessitava de uma lei mais flexível para se desenvolver. Mas será que os agricultores familiares sabem o que foi discutido e o que foi decidido? Será que eles sabem que um dos objetivos principais desta lei era beneficiá-los? E será que eles se sentem beneficiados?

Neste aspecto, propõe-se refletir a respeito do papel da extensão rural, como mediadora desse debate. Dois aspectos presentes na figura do extensionista rural o coloca como possível mediador entre a necessidade do agricultor e a vontade do Estado no momento da elaboração da lei: em uma esfera, a proximidade deste agente em relação aos agricultores, e, em outra esfera, o fato de ser este um agente do Estado e de conhecer os instrumentos necessários para fazer-se ouvir em uma sociedade democrática capacita este profissional para realizar a mediação que falta nesse processo de discussão e elaboração das leis que afetam a agricultura.

Paulo Freire, em 1968, fez uma crítica ao processo de extensão rural. Segundo ele, tal processo apresentava um fluxo de informações unidirecional e impositivo, incapaz de trazer bons resultados. O autor defendia um processo efetivamente comunicativo, dialógico, de troca de saberes, a ser estabelecido entre 0 técnico e o agricultor (FREIRE, 1982).

No mesmo sentido, Peixoto (2008) explica que, a extensão rural entendida como um processo de diálogo, difere conceitualmente da assistência técnica pelo fato de que esta não tem, necessariamente, um caráter educativo, pois visa somente resolver problemas específicos, pontuais, sem capacitar o agricultor. O autor afirma que é por ter um caráter educativo que o serviço de extensão rural é, normalmente, desempenhado pelas instituições públicas de Ater, organizações não governamentais, e cooperativas, mas que também prestam assistência técnica.

Acredita-se que, nos tempos atuais, em que tanto se questiona a respeito do papel da extensão rural, realizar esta troca de saberes e trabalhar para dar voz e visibilidade aos pequenos agricultores pode ser uma das funções mais importantes do extensionista.

Em 06/06/22013, a presidenta Dilma Rousseff assinou o projeto de lei que cria a Agência Nacional de Assistência Técnica e Extensão Rural (ANATER). O objetivo, segundo o ministro do Desenvolvimento Agrário, Pepe Vargas, é garantir que agricultores aumentem a produtividade e renda por meio do acesso à assistência técnica e extensão rural em todas as etapas da atividade. Pretende-se, com o projeto, garantir a aproximação da pesquisa agropecuária com a extensão rural, por essa razão, a ANATER atuará em parceria com a Empresa Brasileira de Pesquisa Agropecuária

(Embrapa)

(http://www.ebc.com.br/noticias/politica/2013/06/governo-cria-agencia-para-

assistencia-tecnica-e-extensao-rural).

É de fato muito importante que existam políticas que visem aumentar a produtividade e a renda dos agricultores Mas esta lei perdeu a chance de fazer do agente extensionista um porta-voz do agricultor. Isto poderia ter acontecido se ela 
tivesse, por exemplo, tornado obrigatória a participação de um agente de extensão em todas as fases de discussão de leis agroambientais.

Vale ressaltar que o projeto da referida agência foi gestado dentro da EMBRAPA, maior empresa de pesquisa agropecuária do Brasil, e justamente por isso, carrega sua marca de produtividade e desenvolvimento, mas não traz em seu bojo, incentivo ou mesmo abertura para que tais profissionais trabalhem no sentido de reduzir a lacuna que existe entre as pessoas que lidam na terra e as pessoas que fazem leis que regulam ou interferem no modo de produzir e de interagir com o ambiente natural.

\section{CONCLUSÕES}

Não restam dúvidas de que a lei é elemento constitutivo dos meios de vida, na medida em que interfere diretamente na maneira como as pessoas desenvolvem suas estratégias de sobrevivência. Os modos de vida dos agricultores são impactados por leis diversas, mas de forma mais gravosa pelas leis ambientais.

Não se desconsidera o caráter protetivo da lei, nem deixa-se de reconhecer que os hábitos e costumes dos agricultores, muitas vezes, interferem de modo negativo no ambiente natural, comprometendo a qualidade de vida das gerações presentes e futuras.

Entretanto, acredita-se que os frequentes conflitos entre a norma e a prática do cotidiano poderia ser amenizada se os agricultores, inclusive os de pequeno porte, fossem verdadeiramente ouvidos e de fato pudessem contribuir para os debates que originam e modelam as leis que diretamente ou indiretamente os atingem.

Neste aspecto, acredita-se que um dos papéis mais importantes da extensão rural no mundo moderno possa ser realizar a mediação entre as necessidades daqueles que lidam na terra e os interesses dos que elaboram as leis que interferem na agricultura. Ser a voz dos agricultores "invisíveis" pode ser uma importante função do agente extensionista dos dias atuais.

\section{REFERÊNCIAS BIBLIOGRÁFICAS}

ANTUNES, Paulo de Bessa. Manual de Direito Ambiental. São Paulo: Saraiva, 2007.

BRASIL. Lei $\mathrm{n}^{\circ}$ 12.651, de 25 de maio de 2012. Dispõe sobre a proteção da vegetação nativa; altera as Leis nos 6.938, de 31 de agosto de 1981, 9.393, de 19 de dezembro de 1996, e 11.428, de 22 de dezembro de 2006; revoga as Leis nos 4.771, de 15 de setembro de 1965, e 7.754, de 14 de abril de 1989, e a Medida Provisória no 2.166-67, de 24 de agosto de 2001; e dá outras providências. Disponível em: <http:// http://www.planalto.gov.br/ccivil_03/_ato20112014/2012/lei/l12651.htm>

CHAMBERS, R. Challenging the professions: frontiers for rural development. London: Intermediate Technology Publications, 1994.

CHAMBERS, Robert e CONWAY, Gordon R. Sustainable Rural Livelihoods: practical concepts for the 21st century. Institute of development studies: Discussion Paper no 296, 1992. 
COSTA T.A., SOARES V.P., RIBEIRO C.A.A.S., GLERIANI J.M. Conflitos de Uso da Terra na Microbacia do São Bartolomeu - Viçosa, MG Floresta e Ambiente 2013; 20(3):281-295. CUIABANO, Renata. Princípios da Proporcionalidade no Direito Ambiental. Revista da Faculdade de Direito da UFPR, v. 36, 2001 p. 317-322.

DUGULIN, Rodrigo de Castro. Imigração sazonal do Vale do Jequitinhonha no séc. XIX: meios de vida, translocalidade e fluxos . Dissertação de Mestrado. Programa de Pós-graduação em Extensão Rural, UFV. Viçosa, 2014.

ELLIS, F. Rural Livelihoods and Diversity in Developing Countries. Oxford: Oxford University Press, 2000.

FRANCO, Maria Sylvia de Carvalho. Homens livres na ordem escravocrata. $4^{a}$ ed.São Paulo:Fundação Editora da UNESP, 1997.

FREIRE, Paulo. Extensão ou Comunicação. Rio de Janeiro: Paz e Terra, 1982.

HAAN, L. de. Globalization, localization and sustainable livelihood. Sociologia ruralis, Oxford (UK), v. 40, n. 3, p. 339-365, jul. 2000.

ZOOMERS, A. Development geography at the grossroads of livelihood and globalisation. Tijdshritf voor economische en sociale geografie, Nijmegen (The Netherlands), v. 94, n. 3, p. 350-362, 2003.

ZOOMERS, A. Exploring the frontier of livelihoods research. Development and change, Oxford (UK), v. 36, n. 1, p. 27-47, 2005.

HAUER, Margit. Conflitos e tensões no uso da terra: agricultura familiar e Legislação ambiental no estado do Paraná. Tese de Doutorado em Engenharia Florestal, Universidade Federal do Paraná, Curitiba, 2009.

HENBICK, Paul et. al. Livelihoods and Landscapes: The people of Guquka and Koloni and thier Resources. (org.) Hebinck, Paul and Lent, C. Peter. Leinden. Brill, Leidein, Boston, 2007.

JACOVINE, Laércio Antônio Gonçalves; CORRÊA, João Batista Lúcio.; SILVA, Márcio Lopes da; VALVERDE, Sebastião Renato; FERNANDES FILHO, Elpídio Inácio Fernandes; COELHO, France Maria Gontijo; PAIVA, Haroldo Nogueira de. Quantificação das áreas de preservação permanente e de reserva legal em propriedades da bacia do Rio Pomba-MG. Rev. Árvore, vol.32, n.2, Viçosa Mar./Apr. 2008.

LELIS, Davi Augusto Santana de. Entre o discurso e a norma: Uma análise sobre o procedimento legiferante em torno do Novo Código Florestal. Dissertação apresentada à Universidade Federal de Viçosa, como parte das exigências do Programa de Pós-Graduação em Extensão Rural, para obtenção do título de Magister Scientiae. VIÇOSA MINAS GERAIS, BRASIL 2011. 
PERONDI, M. A. Diversificação dos meios de vida e mercantilização da agricultura familiar. 2007. $210 \mathrm{f}$. Tese (Doutorado em Desenvolvimento Rural) Universidade Federal do Rio Grande do Sul, Porto Alegre, 2007.

PERONDI, M.A; SIMONETTI, D.; VILLWOCK, A.P.S.. A estratégia de diversificação da agricultura familiar: o caso da comunidade rural de São João em Itapejara d'Oeste - PR. CONGRESSO DA SOCIEDADE BRASILEIRA DE ECONOMIA ADMINISTRAÇÃO E SOCIOLOGIA RURAL, 48. 2010. Campo Grande, MS. Anais... Campo Grande: UCDB, 2010. 1 CD-ROM.

PEIXOTO, Marcos. Extensão Rural no Brasil - uma abordagem histórica da legislação. Consultoria Legislativa do Senado Federal. Centro de Estudos. Disponível em: http://www.senado.gov.br. Acesso em junho de 2013.

THOMPSON, E. P. Senhores e caçadores. Rio de Janeiro: Paz e Terra, 1987.

TOURINHO, Luiz Anselmo Merlin; PASSOS, Everton. O Código Florestal $\mathrm{Na}$ Pequena Propriedade Rural: Um Estudo De Caso Em Três Propriedades $\mathrm{Na}$ Microbacia Do Rio Miringuava. R. RA'E GA, Curitiba, n. 12, p. 221-233, 2006. Editora UFPR.

SOUZA, Jessé. A construção social da subcidadania: para uma sociologia política da modernidade periférica. Belo Horizonte, Editora da UFMG, 2003.

STRECK, Lenio Luiz. Hermenêutica Jurídica e(m) Crise. 11.ed. Porto Alegre: Livraria do Advogado, 1998. 